\title{
TECHNOLOGICAL ENLIGHTENMENT IN RUSSIA
}

V itali Gorokhov, Russian A cademy of Sciences and U niversity of Karlsruhe

\section{THE FIRST STEPS OF ENGINEERING EDUCATION IN RUSSIA}

Peter the Great brought technological enlightenment to Russia. In his lifetime, two special schools for training engineers were established, the Engineering School in 1700, and the M athematical-N avigation School in 1701. Peter the Great introduced engineering training into other institutions as well, not only into the Naval A cademy, but also regimental schools and even religious colleges. (See M echanics and Civilization, 1979.) Teaching at that time remained on a primitive level, if seen from the late twentieth century.

Gradually, the profession grew more complicated and demanded greater skills and more technical knowledge. M ining enterprises were the first to feel the lack of properly educated engineers. To meet their needs the Russian M ining School was set up in 1773 by M ikhail Soimonov (1773-1804), an enthusiast of higher education in the country and an organizer of better mining in Russia.

The program was intended for four years-though gifted students were allowed to graduate earlier than that. Those who were not clever enough got a rank of non-commissioned officer upon leaving the school. ("If they are not able to show more diligence," the state will stop wasting money on their education.) The students themselves had to translate textbooks. The school's printshop published original works, too. At first, these were used solely inside the school. L ater, Soimonov, who was convinced that, "These books can be useful in factories and mines," ordered several copies to be sent to each factory (Goldenberg, 1973).

The engineering schools lagged behind science institutions in the theoretical training of students, since they oriented themselves towards the practical training of students and the practical needs of Russian industry. Practical teaching methods were better suited for apprenticeship. Engineers with many years of practical work behind them explained to small groups of students, or even to single students, how to build constructions and assemble machines and 
how to become a practical engineer. Theory was mainly dealt with as applied to practical demonstrations. Textbooks mainly dealt with applied knowledge. The mathematical education of engineers was elementary.

Changes began after 1794, when Gaspard M onge founded the Polytechnic Institute in Paris. He steered this educational institution towards a better theoretical training. Germany, Spain, Sweden, and the U nited States of A merica followed in France's steps. In 1809, the Institute of the Corps of Engineers of Rail Transport was set up in Russia. Its first director was the Spaniard, A. Betancourt (1758-1824), who was Monge's pupil and who had previously been a professor at the Polytechnic Institute in Paris. By distinction from the Paris School, on Betancourt's explicit suggestion, the final year in Russia was totally dedicated to practical work, so that, "U pon leaving the Institute the students should be acquainted with theoretical sciences and their application to engineering art" (Bogolyubov, 1976, p. 118). This institute was instrumental in promoting engineering activity in Russia.

Betancourt also proposed a program of setting up a network of schools for training operating and service staffs. The program was accepted, and a militaryconstruction school and a school for railway guards were established in St. Petersburg. L ater, in 1884, this program was extended by Ivan W yshnegradsky (1831-1895). He was a prominent scientist (mathematician and machine-builder) and a member of the St. Petersburg A cademy of Sciences. He argued that technological enlightenment should embrace all levels of industry; it should be the higher schools that trained engineers, the secondary schools that trained technicians-and there were also to be schools for foremen and workers (Bogolyubov, 1976, p. 361).

In the late nineteenth and especially in the early twentieth century, free Sunday and night schools in plants and factories for workers and their children were mushrooming across the country.

M oreover, by the late nineteenth century, theoretical training for engineers and higher technological education for other technical workers had became a must. At that time, many vocational and secondary technical schools had already been transformed into higher technical schools and institutes. The Technological Institute in St. Petersburg, for example, had been created in 1862 
on the basis of a school for foremen that was intended for the lower social strata, such as peasants and artisans. The same can be said about the St. Petersburg Institute of Electrical Engineering, one of the first schools of its kind. It was set up in 1891 on the basis of the School of Post and Telegraph (1886). In M oscow, a Higher Technical School was established in 1868 following the reorganization of a vocational school (dating from 1830). Its purpose was declared to be "to provide higher education in the engineering and chemical professions." These new higher educational establishments concentrated on the theoretical side of their curricula.

Bogolyubov (1976, p. 108) says: "As the nineteenth century was drawing to an end, an increasing number of engineering problems were more or less profoundly investigated from a theoretical point of view. New technical branches appeared, which owed their existence to theoretical research." Scientific research underwent changes to better serve the requirements of rapidly progressing practical engineering. Physics and mathematics figured as the core disciplines of the theoretical training of future engineers.

\section{ENGINEERING SOCIETIES AND EXPERT JOURNALS}

In their efforts to promote technological knowledge, higher education institutions were working side by side with technical societies. The Russian Technical Society, formed in 1866, proclaimed as its aim "the development of technology and technical industries in Russia" through readings, meetings and public lectures about technology; dissemination of theoretical and practical knowledge through periodical and other publications; promotion of technological enlightenment (Short Survey, 1893). In 1867, the society launched its publication, Transactions of the Imperial Russian Technical Society. The society had departments in many Russian cities. In 1876, it also began to publish the Transactions of the Commission for Technological Education (set up in 1868). L ater the society edited still another journal, Technological Education. Late in the nineteenth century the society started a popular journal on technical novelties: Technician. (Between 1884 and 1889, it was edited by a prominent Russian engineer and philosopher of technology, P. K. Engelmeyer.) There were many other journals, the most interesting of which was Technological Collection and Herald of Industry, a journal of technical discoveries, innovations, and general news in the field of technology and industry. 
The Polytechnic Society was set up in M oscow in 1877 at the M oscow Higher Technical School. It published its ownBulletin. In 1915, this journal and the Herald of the Society of Technologists were transformed into the journal, Herald of Engineers. The charter of the Polytechnic Society declared that one of its core aims was "to unite the successive classes of the M oscow Higher Technical School in a common effort in science and industry, based on high moral principles and religion, to provide them with an opportunity to share their knowledge, to pursue advances in science and technology and to promote their progress in Russia" (Forty Years of the Polytechnic, 1917).

There was a society that explicitly had as its special aim the furthering of technological enlightenment. In its charter, adopted on J une 4, 1869, it stated that its aim was "to promote improvement and dissemination of technological enlightenment in Russia; the primary aim is to introduce improved technological methods into those branches of industry and handicrafts that are of a wide practical importance." To reach these aims the society had the right to "(a) set up technical schools and workshops; (b) to organize libraries, exhibitions, and museums of industry and crafts; and (c) to publish books in all branches of technology" (Charter of M oscow Society, 1980).

The Society for Promoting A dvances in Experimental Sciences and Their Practical A pplication, at the Imperial M oscow U niversity and at the Imperial M oscow Technical School named after Professor Christian Ledentzov, deserve special mention. It was operating in M oscow between 1909 and 1918. Professor Ledentzov of the Imperial M oscow Technical School bequeathed 100,000 rubles to set up this society on an indispensable condition, that

All members of the society, irrespective of their sex, social status, academic degree and nationality should promote the Society's aims stated in the charter. This is mainly to be done through grants for the promotion of discoveries and inventions that can, with minimum capital investments, bring greater advantages to the majority of the people. These grants should be used to help implement these discoveries and inventions, not to trail behind them as a set of prizes, subsidies, and medals." L edentzov stipulated in his will that "the Society should cooperate with the innovators not so much by granting money as by 
promoting the maximally profitable utilization of their discoveries and inventions. The conditions of such cooperation should be agreed on in written form beforehand. In any case, part of the profit should go to the Society's special fund intended exclusively for the practical implementation of discoveries and inventions (Annals of the Ledentzov Society, 1910, p.10)."

The society's charter stated:

1. The Society's aim is: (a) to promote discoveries and research in the natural sciences; (b) to promote technological innovations and improvements; (c) to test and implement scientific and technological discoveries and inventions.

2. This aim can be reached by (a) giving advice and instructions and discussing the submitted projects, issuing expert opinions about scientific and technological discoveries and inventions, distributing grants for the implementation of scientific research and innovations, setting up laboratories and other similar organizations; (b) publishing the Society's works, establishing libraries, carrying out public readings and discussions, organizing museums and exhibitions; (c) working to allow people recommended by the Society to participate in special works in the teaching institutions and departments of the Imperial M oscow University and the Imperial M oscow Technical School; (d) making the best possible use of discoveries and inventions on the conditions agreed beforehand with innovators so that part of the profits go to the special fund for the promotion and implementation of discoveries and inventions: some other part of the profits should be use to strengthen the Society's finances. The correlation between the two parts should be decided on by the Society's general meeting; (e) awarding medals, prizes and diplomas for scientific and technological research and discoveries (M oscow State Historical Archive, p. 91).

The society channeled 100,000 rubles out of its extraordinary balance sheet to set up a library and to replenish it annually. It was regarded as a form of 
promotion of research and discoveries and a base for expert and consultative efforts.

Today, we can learn a lot from this society's experience. W hat is very important is its main idea to give money not to ready-made products but to ideas that may bring practical advantages in the future and, in this way, effectively to support gifted researchers and inventors. To be efficient, a similar society could be founded as an international organization. This alone could ensure a genuinely independent assessment of technological projects. We should today be concerned not so much with isolated technological assessment as with care for the socialhumanitarian and ecological sides of any project. A $n$ assessment of these aspects should take into account specific social and cultural features of all countries.

\section{THE ROLE OF THE PHILOSOPHY OF TECHNOLOGY}

The philosophy of technology today still has an important role to play in technological enlightenment. Back in 1898, P. K. Engelmeyer (see Gorokhov, 1997), the Russian engineer and philosopher of technology mentioned above, wrote:

(1) In any field of human endeavor a transition from the idea to an object, from an aim to its practical implementation, involves special technologies. All of them have many features in common. One of the tasks of philosophy of technology is to identify these common features:

(a) What the relationships are between technology and culture as a whole?

(b) The relationships between technology and economics.

(c) Elaboration of the problems of technological innovation.

In other words, technology is nothing more than a wheel in the gigantic clock of the human community. It can study the mechanism of this clock, but it is unable to overcome its limits to define the place of this wheel and its function in the overall mechanism. Only philosophy of technology can be adequate to this 
larger task. (See Engelmeyer, 1898, 1900, and 1910 [1968].)

I believe that the humanization of engineering activity and engineering education is still one of the main tasks of the philosophy of technology. To reach this goal would be an outstanding advance in the philosophy of technology today and for the future. In 1912 Engelmeyer published his book Philosophy of Technology (1912), based on the lectures he had delivered to a circle of students of the M oscow Higher Technical School. Later, when many engineers had asked him what the philosophy of technology was, what its aims were, and how it could be applied in practice, he replied to their questions in the second issue of the Bulletin of the Polytechnic Society in 1913. His general answer (p. 113) was, "This will be a new science that will clarify the role of technology as a cultural factor." In an article, "A dvantages of the Philosophy of Technology," that appeared somewhat later, he explained that the problem of technology versus culture could not possibly be solved by the technical sciences; by themselves they would not be able to overcome the limits of technology. To solve this problem, one would have to look at technology from afar, to cross narrow limits, and "to look into the neighboring regions of science, art, ethics, law, politics, etc., in search of technological impacts" (Engelmeyer, 1913, p. 351). As a new science, the philosophy of technology would overcome the limits of technology, that is, of methods and procedural necessities, arriving at a certain generalizing stage. (In the same way, technology had had to overcome the limits of elementary techniques, that is, of crafts.) "As a theory of culture, philosophy of technology raises technology to the level of epistemology, ethics, and aesthetics. With time, it can evolve into a 'technological world outlook.' "

Philosophy of technology makes possible a broader humanitarian approach to technology. It would have been inconceivable without a humanitarian movement among engineers. In Russia, the humanitarian trends were evident first of all in what the Polytechnic Society and the Russian Technical Society were doing. Russian engineers displayed a great interest in the discussion of general technological ideas and humanitarian issues.

One such work was A. Pavlovsky's Technological Advances and Their Impact on Civilization (1896). A nd Engelmeyer paid particular attention to what this industrial engineer had to say. In one section, "Technology and Its Ties with Philosophy," Pavlovsky (1896) wrote: "We all know that early in this century 
natural science was blossoming and that it had led to advances in philosophy. There is no doubt that in the course of time technology will bear a no less beautiful fruit. The philosophy of knowledge made the first steps in technology easier. The time has come for technology to chart the ways for other branches of knowledge, and for philosophy to lead with unprecedented speed and energy."

This seems still to be valid today.

Engelmeyer proved to be a really farsighted and practical philosopher of technology. The theoretical and practical advances hinted at by Engelmeyer have yet to be launched (and we have to work at them, and not just wait).

One can say that the Zeitgeist of the time prompted Engelmeyer in his philosophy of technology, and that there was a responsive public among Russian engineers eager to listen to him. Today, following Engelmeyer's example and spreading humanitarian ideas of technology among engineers and in the society as a whole remains one of the practical tasks of the philosophy of technology. A key is to establish philosophy of technology as an indispensable part of the curriculum at least in the higher technical schools. Science and technology can become humane through education. But this practical implementation of philosophy of technology is yet to come.

\section{THE INVENTING AND DESIGNING PROCESS: IMPACTS OF ADVANCED TECHNOLOGY ON PHILOSOPHY OF TECHNOLOGY}

One important part of this practical philosophy of technology was a description of the inventing and designing process in technical creative activities-a description fashioned for educational goals. The first such descriptions were written in Germany around the end of the nineteenth and the beginning of the twentieth century (W ridigen, 1892; Rasch, 1899; DuBois-

Reymond, 1906; and Eath, 1924). At the root of Engelmeyer's theory of technical creative activities is what he says about the so-called "triact." The triact theory of technical creative activities was first propounded by Engelmeyer before the M oscow Polytechnic Society in 1889 , but the paper was not published until later (1899).

The process is described by Engelmeyer in the following way: 
There is not a sufficient difference between free invention and socalled designing in previous explanations. If, in designing a solution suggested by particular tasks, some range of self-activity is left for a technician, and if this self-activity is homogeneous in quality with an inventor's activity, the two take part in designing in different proportions. But designing, because it is methodical, is better susceptible to analysis; it is more transparent than the hidden and feverish work of an inventor. Therefore, I first analyzed the designing process, and then checked the data with examples of invention, continuing this checking, during many years and with respect to more distant examples taken from the reliable examples of scientific and artistic creative activity. I was sure that my main view was applicable to all varieties of human creative work. M y view is that the complete process of invention begins when the unconscious soul conceives a new idea, but it then falls into three different acts. In the first, only the idea is created; in the second, the scheme or a detailed plan is elaborated; and in the third the thing is carried out and completed. From this point of view I labeled the invention process as a triact and more than once described this view in the Russian, German, and French literature during the period of time from 1889 to 1900. (See Engelmeyer, 1908; also 1895, 1900, and 1910.)

A ccording to Engelmeyer's report, his theory had, al ready at that time, been commented on in the literature. It also found application in the patent business.

Engelmeyer set himself the task of analyzing and describing the design process, and he thought the task was dictated, primarily, by the demands of teaching.

According to Engelmeyer's opinion, human creative activity is an accumulation of three factors: wish or intuition, knowledge, and know-how. He also distinguishes three types of products of the activity (he defines the activity as the work process itself): ideas, processes, and material things, or articles in space. In accordance with these distinctions, he divides the designing process into three 
stages: (1) creating the general layout, (2) developing a general scheme from this layout, and (3) elaborating the scheme in detail up to and inclusive of complete drawings.

For the analysis, he takes as an example the complete systematic designing process with respect to a new and fairly complicated machine. "Such a process will give us as large a number of different factors as possible." Simpler cases will allow the reduction of this space.

His method is especially good for teaching.

As an illustration, Engelmeyer quotes a paper he wrote about automobiles in a report to the Polytechnic Society, October 13, 1907:

Those who were present will remember that at first we considered as a principle the parts of an automobile, that is the totality of its main essential bodies, those bodies, without which the machine cannot be called an automobile. Then we considered schematically developed systems of up-to-date automobiles; and at this second step, giving only a general conception of the automobile, my report was finished. Then everybody ... could become acquainted with the constructive details of these machines (p. 406).

Let us sum up. What gives us a general description of the design process? First, it includes a developed description of both the complete design process and its different partial versions. It is well demonstrated by Engelmeyer in a number of concrete examples from the practice of machine building. Today his description would no longer be adequate, and it has, in large measure, been superseded by the contemporary theory of design. But Engelmeyer correctly guessed the structure of the problem, and he outlined an early version of its solution. Second, he provided a clear classification of different methods of describing or presenting a machine (and, in general, of any technical system), which is still applicable in designing, engineering, and the technical sciences. Third, his description offers the possibility of making clear distinctions between inventing, designing, engineering, and science. 
Although in each of these types of activity the complete triact is applicable, free invention can be attributed to the first act (where it is clearly predominant). Designing, which is best connected with scientific research and calculations, can be attributed to the second act. This involves work with a scheme or layout-that is, with drawing and paper-and can with full right be attributed to the stage of so-called draft designing. Engineering or construction, which involves the elaboration of a machine design and is materialized during the production process, can be attributed to the third act.

At the end of the nineteenth and the beginning of the twentieth century, designing, as a special type of engineering activity, was not yet developed enough or sufficiently separated from engineering or construction. In fact, Engelmeyer accurately assessed the tendency toward development of this separate activity, and his theoretical (more correctly, his philosophical-methodological) formulation played a role in solving the problem.

Engelmeyer, finally (1916, pp. 97-108), developed his theory of creative work in successive steps, going from the particular to the general case, from clearer and simply analyzed methodological types of designing through the invention (the main subject of his concern) to a general theory of creative work. The first two cases, designing and invention, appeared to him as particular problems of a general theory of creative activities.

\section{REFERENCES}

Annals of the Ledentzov Society for Promoting Advances in Experimental Sciences and Their Practical Application. 1910. M oscow.

Bogolyubov, A. N. Teoria mekhanismiv i machin $v$ istoricheskom razvitii ee idei [Theory of mechanisms and machines in the historical evolution of ideas]. 1976. M oscow: Nauka. Charter of the Moscow Society for Technological Enlightenment. 1980. M oscow.

DuBois-Reymond, Alard. 1906. Erfindung und Erfinder. Berlin: Springer.

Eath, M ax. 1924. Lebendige K räfte: Sieben Vorträge aus Gebiet der Technik. Berlin: Springer. Engelmeyer, P. K. 1895. "Das Erfinden," Kölnische Zeitung, no. 138; 15, 16, 18 F ebruary. . 1898. Technological Results of the 19th Century. St. Petersburg. 1899. "Designing of M achines: Psychological A nalysis," Technical Education, no. 3. 1900a. "Philosophie der Technik: Eine neue Forschungs-richtung," Prometheus, nos. 564, pp. 659-692, and 565, pp. 707-710. . 1900b. "Allgemeine Fragen der Technik," Dinglers Politechnisches J ournal, 315:13. 1907. "What Is It? Principle, System, and Construction in M achines," Bulletins of the 
Polytechnic Society, no. 7.

. 1908. "D octrine about Invention," Bulletins of the Polytechnic Society, no. 4.

- 1910. Die D reiakt als Lehre von der Technik und der Erfindung. Berlin: Heymann.

. 1911. "Philosophie der Technik," in Atti del IV Congresso Internationale di Filosofia

(Bologna), vol. III. Nendeln/Liechtenstein: Klaus Reprints.

. 1912. The Philosophy of Technology, issues 1-4.

- 1913a. "The Tasks of the Philosophy of Technology," Bulletins of the Polytechnic

Society, no. 2.

. 1913b. "A dvances in the Philosophy of Technology," Bulletins of the Polytechnic Society, no. 6.

. 1916. "Heurology, or a General Theory of Creativity," in Q uestions of the Theory and Psychology of Creativity, vol. 7. K harkov. Pp. 97-108.

Mekhanika i tzivilizatsia XVII-XIX vv [M echanics and civilization in the 17th - 19th centuries]. 1979. M oscow: Nauka.

Moscow State Historical Archive. Record Group 224, In v. 1, File I.

Pavlovsky, A. 1896. Technological Advances and Their Impact on Civilization. St. Petersburg.

Rasch, E. 1899. Zum Wesen der Erfindung. Hamburg.

Short survey of the History of the Imperial Russian Technical Society from Its First Foundation to January 1, 1893. 1893. St. Petersburg.

Wridigen, B. 1892. Von Erfinden: Eine Untersuchung über die Bedingung nützliche E rfindungen zu machen und deren Verwehrtung. $\mathrm{K}$ arlsruhe. 